\title{
êRALUACIÓN DEL ACUERDO DE NUEVA IMPERIAL Y SU IMPACTO EN LA REALIDAD INDÍGENA CHILENA, DESDE LA PERCEPCIÓN DE LA DIRIGENCIA AYMARA ${ }^{1}$
}

\section{René Patricio Aguilera Barraza²}

Sociólogo, Universidad Arturo Prat. Candidato a Magíster en Antropología, Universidad Católica del Norte de Antofagasta y Universidad Tarapacá de Arica. Dirección: Aníbal Pinto № 775, Coquimbo (Chile). E-mail: reneaguilera912@hotmail.com. Tlfno: 56 - 51 - 284546.

\begin{abstract}
Resumen
El escrito revisa críticamente, desde el pensamiento de la dirigencia aymara, las repercusiones que tuvo el Acuerdo de Nueva Imperial en la realidad indígena chilena, protocolo acuñado, el año 1989, entre los pueblos precolombinos (Mapuche, Rapa Nui, Kolla, Atacameño y Aymara) y los partidos políticos opositores a la dictadura de Augusto Pinochet Ugarte. En él, el movimiento indígena contraía la obligación de apoyar al candidato presidencial Sr. Patricio Aylwin Azocar. A cambio, el entonces candidato de la Concertación de Partidos Políticos por la Democracia, si era electo Presidente de la República, se comprometía a resolver las siguientes demandas indígenas. Primero, elaborar un marco jurídico en favor del desarrollo de los pueblos originarios, punto resuelto con la promulgación de la Ley Indígena $\mathrm{N}^{0}$ 19.253, un 5 de octubre de 1993. Segundo, reconocer constitucionalmente a los pueblos indígenas; y tercero, ratificar el Convenio 169 de la OIT en territorio nacional. El punto dos y tres del Acuerdo de Nueva Imperial permanecen pendientes hasta nuestros días, sin que exista, por parte de las elites de poder que rodean al Estado, la voluntad política para ser aprobados.
\end{abstract}

\section{Palabras claves}

Ciudadanía, Etnicidad, Multiculturalismo, Pluralismo Jurídico, Interculturalidad, Chile.

\begin{abstract}
This paper is a review of the way in which the Agreement of Nueva Imperial impacted in the Chilean indigenous scenario, from the critical perception of the aymara leadership. The protocol was signed in 1989, between the pre-Columbian groups (Mapuche, Rapa Nui, Kolla, Atacameño and Aymara) and the political parties opposed against the dictatorship of Augusto Pinochet Ugarte. According to the contents of the agreement, the indigenous movement was obligated to support the presidential candidate Mr. Patricio Aylwin Azocar. In return, the
\end{abstract}

\footnotetext{
${ }^{1}$ Artículo elaborado en base a la información obtenida en la investigación de Tesis titulada: Las Representaciones Sociales del Estado que han elaborado las Comunidades Andinas del Norte de Chile. Estudio realizado para obtener el grado de Licenciado en Sociología y el Título de Sociólogo. Trabajo dirigido por el Académico Dr. Hans Gundermann Kröll.

${ }^{2}$ Sociólogo, Universidad Arturo Prat, Iquique. Candidato a Magíster en Antropología, dictado por la Universidad Católica del Norte de Antofagasta en conjunto con la Universidad Tarapacá de Arica, con Sede en el Instituto de Investigaciones Arqueológicas y Museo "R. P. Gustavo Le Paige, s.j.", San Pedro de Atacama. Actualmente, en proceso de revisión de su Tesis denominada: Resistencia y Ciudadanía en la desperuanización de los valles tarapaqueños, en el período histórico de 1900 a 1930. Dirigida por el académico Dr. Sergio González Miranda; profesor lector Dr. Héctor González Cortez.
} 
candidate, if elected as President of the Republic, would attend the following indigenous demands: First, to establish a legal structure for the economic development of these groups. This point was accomplished with the Indigenous Law No 19,253, 5 of October of 1993. Second, to recognize the indigenous groups in the Constitution; and third, to ratify the ILO Convention 169 in the national territory. Points two and three in the Agreement of Nueva Imperial are still pending to be accomplished, and there are not indicators nor intention from the empowered elites to accomplish them.

\section{Key Words}

Citizenship, Ethnicity, Multiculturalism, Legal Pluralism, Interculturality, Chile.

\section{Agradecimientos}

Al profesor Hans Gundermann Kröll por permitir mi participación en el proyecto de investigación, donde floreció el presente artículo. A los dirigentes andinos, en especial a la señora Fresia Vilca, quienes con su pensamiento contribuyen a la construcción de una sociedad con mayor igualdad para los pueblos indígenas en Chile. A mis padres y a mi familia, habitantes de macondo que transitan entre la precordillera de Andacollo y el Valle de los Sueños de Illapel.

\section{Introducción}

$E^{\prime}$ Acuerdo de Nueva Imperial, a fines de los ochenta, instauró en Chile un nuevo escenario de relaciones sociopolíticas entre administraciones del Estado y pueblos indígenas. Fue un pacto de dominación en el que los originarios depositaron una serie de expectativas y de proyectos, producto del giro que la política estatal tomó, desde ese momento, para intervenir en la realidad indígena y para dar respuesta a sus demandas ciudadanas. Pasados diecisiete años y tres gobiernos de elección popular, todos ellos de la Concertación de Partidos Políticos por la Democracia, los resultados obtenidos con el protocolo de Nueva Imperial no han sido los esperados por los pueblos prehispánicos.

Este escrito analiza a través de la percepción de la elite dirigencial aymara los avances logrados y los retrocesos que en materia indígena se han producido con el Acuerdo de Nueva Imperial en la comunidad política nacional. Para capturar la impresión andina el estudio se basó en un conjunto de entrevistas, que permitieron desarrollar un análisis discursivo sobre la subjetividad aymara, procurando conocer no sólo la evaluación que realizan los autóctonos de los Andes sobre el pacto político de 1989; sino también la evolución que ha tenido el pensamiento social de los pueblos precolombinos desde la firma de tal pacto de dominación. Esta reflexión indígena sanciona, en la actualidad, el agotamiento del Acuerdo de Nueva Imperial y la búsqueda de una nueva institucionalidad para regir las relaciones entre originarios y sociedad civil no indígena. Esta institucionalidad debería fomentar la construcción de un Estado pluriéntico y un ordenamiento jurídico pluricultural para Chile, lo que concedería potenciar una democracia con mayores grados de inclusión y una ciudadanía de mayor representatividad para los pueblos originarios en la comunidad política nacional. En un contexto histórico caracterizado por el multiculturalismo y por el reconocimiento de las 
diferencias étnicas, la opinión aymara establece la persistencia de relaciones de exclusión y de discriminación sobre los originaros en la sociedad chilena.

\section{Consideraciones Metodológicas}

Para desarrollar una evaluación sobre el Acuerdo de Nueva Imperial y su impacto en la realidad indígena chilena a partir de la subjetividad andina, se tuvo que definir un espacio de anclaje donde se depositaran las percepciones que la dirigencia nativa de los Andes chilenos poseyó para fabricar una opinión sobre el pacto político de 1989. Existen también en la realidad social otros espacios de anclaje para objetivar una impresión de un objeto, como son el teatro o la pintura, por nombrar algunos ámbitos de conexión y de materialización de las percepciones que un individuo crea de un objeto en la realidad social. Para este escrito la dimensión que cumplió la función de anclaje fue el lenguaje (Jodelett, 1998). El lenguaje por si sólo no bastó para conocer los variados sentidos que existen alrededor del pacto de dominación multicultural nacido con el Acuerdo de Nueva Imperial, por lo que se debieron dar necesariamente actos reflexivos del lenguaje que permitieran describir ciertas características del mismo y transformar esas particularidades en realidades válidas por encima de otras nociones existentes y referentes a ese mismo objeto. Esos actos lingüísticos se definieron, en el manuscrito, como discursos (Foucault, 1997). Ellos fueron los depósitos de las diferentes maneras en que la experiencia individual o social ha conocido un objeto. Se trata de acciones de enunciación sostenidas en la capacidad de reflexión de los individuos y de los grupos sociales que concedieron crear y recrear historias, juicios, valoraciones, representaciones y mitos concernientes al protocolo político de 1989 en la realidad social chilena.

Sin embargo, para que la construcción de los discursos sobre el Acuerdo de Nueva Imperial no se transformaran en ideas ahistóricas en el presente texto, se ligaron a sus condiciones políticas y socioeconómicas a las que hacen referencia. Para concretar el proceso de localización del discurso con su fase histórica particular se consideraron las condiciones de formación discursiva. Estos requisitos tienen relación con procesos económicos, sociales y políticos, con instituciones, formas de comportamientos, sistemas de normas, tipos de clasificación, entre otras condiciones. Estos requisitos no definieron la constitución interna del discurso, sino que establecieron las circunstancias en que aparecen los discursos sobre alguien o sobre algo. Las condiciones de formación ponen en movimiento al discurso; lo sitúan en los límites en el que fue creado; lo provee de sentido; le otorga materialidad; dota al discurso de un cuerpo histórico del que es inseparable (Foucault, 1997). Para

este escrito esas condiciones de formación discursiva hicieron referencia a los siguientes hechos y contenidos: al retorno de los gobiernos de elección popular en Chile, al Acuerdo de Nueva Imperial, a la Ley Indígena No 19.253, a la Corporación Nacional de Desarrollo Indígena (CONADI), al Convenio 169 de la OIT., a la constitución de la República chilena, al nacionalismo, al multiculturalismo, a la discriminación y al patrimonio histórico indígena, entre otros contenidos.

(C) René Patricio Aguilera Barraza. Publicado en AIBR. Revista de Antropología Iberoamericana, Ed. Electrónica 
La reconstrucción de las percepciones que los indígenas de los Andes tuvieron en lo relativo al pacto de dominación de Nueva Imperial no persiguió solamente conocer las formas de aprehensión de la dirigencia aymara para crear y para reproducir la realidad sicosocial de un objeto; sino que además, apuntó a captar la particular dinámica que el Estado chileno ha impuesto a las relaciones sociopolíticas que lo ligan con los pueblos indígenas, en un contexto histórico envuelto por el discurso de la Multiculturalidad y por un lenguaje político de reconocimiento de las diferencias étnicas de los pueblos prehispánicos.

Para apoderarse de los discursos que la dirigencia aymara tuvo sobre el acuerdo de Nueva Imperial se desarrolló un trabajo de entrevistas en el marco del Proyecto FONDECYT: "De Indio a Ciudadano: Etnicidad, Identidad étnica e incorporación indígena a la sociedad nacional en el norte de Chile en comparación con los Andes de Perú, Bolivia y Ecuador (1824 -1995)", N 19070644. Fueron entrevistas realizadas en el período de 1999 al 2000. Se dirigieron a conocer, mediante la percepción de la elite dirigencial aymara, las distintas representaciones que para el mundo prehispánico local ha personificado el Estado, desde tiempos coloniales hasta nuestros días. Este es un proyecto encabezado por el profesor Dr. Hans Gundermann Kröll, donde cumplí labores de asistente de investigación. Asimismo, estos discursos relativos a la realidad investigada fueron extraídos de periódicos y de entrevistas cedidas. Se trata de un conjunto de discursos que buscaron entregar un cuadro sobre el pensamiento que teje el mundo andino sobre los avances y sobre los retrocesos que el Acuerdo de Nueva Imperial ha establecido en la realidad indígena chilena.

\section{El Acuerdo de Nueva Imperial en la realidad indígena chilena.}

La derrota plebiscitaria que obtuvo en 1988 el general Pinochet, donde la mayoría de la ciudadanía nacional resolvió la no continuidad del régimen militar en el poder gubernamental, concedió a los pueblos indígenas, en un contexto social de retorno a los gobiernos de elección popular en Chile, acuñar nuevos contenidos al pacto de dominación sostenido con las elites de poder que influyen el actuar del Estado. Ese nuevo pacto de dominación, suscrito entre la Concertación de Partidos por la Democracia y los pueblos prehispánicos, se denominó Acuerdo de Nueva Imperial, un instrumento político que otorgó promover a través de los aparatos estatales una ciudadanía diferenciada en la que se resaltaban los códigos étnicos de la población precolombina, que en épocas pasadas habían sido negados por el accionar estatal para la integración del indígena en la comunidad nacional. Asimismo, ese protocolo facilitó modificar la demanda ciudadana dirigida históricamente por los pueblos indígenas al Estado. Desde ahora, junto con seguir manifestado la tradicional solicitud por educación, por salud, por caminos, por seguridad policial, por subsidios agroproductivos, entre otras exigencias clásicas; también comunicaba una petición de autonomía, de derechos colectivos, de respeto por lo étnico y de un desarrollo con identidad para la sociedad prehispánica chilena. En la conciencia social andina el Acuerdo de Nueva Imperial poseyó la siguiente valoración.

(C) René Patricio Aguilera Barraza. Publicado en AIBR. Revista de Antropología Iberoamericana, Ed. Electrónica 
El Acuerdo de Nueva Imperial fue importante, en ese minuto, ya que no eran reconocidos los pueblos indígenas en el país. Hoy en día sí son tomados en cuenta, de alguna manera o con complicaciones, pero son tomados en cuenta (Sr. Antonio Mamani. Dirigente de Aymar Marka. Organización aymara de la Provincia de Iquique, ex-Subdirector de la Corporación Nacional de Desarrollo Indígena, Jurisdicción - Subdirección Norte (CONADI) 1993 - 1999. Actualmente, Secretario Ejecutivo de la Corporación de los Municipios Rurales de la Provincia de Iquique, 2006. Entrevista, 9 de agosto de 1999. Líneas: 61 - 63. Pág.: 3).

Este pacto de dominación amparado en el reconocimiento de las diferencias étnicas otorgó, en el ocaso del siglo veinte, una participación social y una representación política al indígena distinta a la desarrollada en la membresía de la ciudadanía republicana de contextos históricos pasados, la cual promovía la igualdad política entre los individuos, obviando los rasgos étnicos de los originarios. Tales frutos alcanzados con el protocolo político de 1989, para la subjetividad andina, sólo fueron producto del momento coyuntural que vivía la sociedad chilena, que buscaba fuertemente librarse del germen del autoritarismo; que ser resultado de una praxis conciente de las elites de poder que rodean al Estado por elaborar una política estatal pertinente al desarrollo de los pueblos vernáculos de la América Morena en Chile. El siguiente registro oral exhibe los pros y los contras que la dirigencia indígena veía en una posible alianza con la Concertación de Partidos por la Democracia, para modificar la posición estructural y para resolver la demanda de los pueblos prehispánicos, en un nuevo contexto sociopolítico marcado por los gobiernos de elección popular para la sociedad chilena.

Por eso, yo siempre me pregunto, ¿fue coyuntural la situación de la Ley indígena? Yo creo que sí, si no se da este contexto, si no se hubiera dado este proceso de 17 años de dictadura, con una cantidad de detenidos desaparecidos, con muertos y toda la cosa, no se hubiese abierto su alma, su corazón para tanta demanda de todo tipo que había; y ahí empezamos nosotros, calzamos justo en el engranaje y entró la Ley. Pero, nosotros no estamos en una pelea de 17 años de dictadura, nosotros vamos ya caminando 500 años de dictadura, la salida o no salida de Pinochet en el tema indígena no iba a cambiar nada. Encontrar otro escenario con distinta coartación de derechos, íbamos a avanzar, en algunas cosas, pero nuestra posición como pueblo iba a seguir con el mismo problema (Sr. Zenón Alarcón. Dirigente del Pacha Aru. Organización aymara de la Provincia de Arica. Actualmente, es Consejero Nacional Aymara frente a la CONADI (2004 - 2008). Entrevista, 2 de julio de 1999 Líneas: 17 - 24. Pág.: 2).

La irrupción de una temática y de una demanda indígena en el discurso de los originarios para platicar con las administraciones del Estado, al cierre del siglo veinte, facilitó observar al interior de la realidad social nativa, que las acciones de negación sobre los rasgos étnicos de las agrupaciones prehispánicas impulsadas desde el nacimiento del Estado republicano, ya sea en su versión peruana o ya sea en su versión chilena, no simbolizaron solamente procesos de olvido y de desintegración de su matriz sociocultural. Del mismo modo, esas prácticas de depreciación y de negación, implicaron para otra parte de la sociedad natural de los Andes un reforzamiento de su identidad autóctona.

Este proceso de valorización positiva de su identidad étnica motivó a los indígenas, a finales de los años ochenta, debatir con los grupos de poder que influyen el actuar del Estado la necesidad de redefinir las obligaciones y los derechos ciudadanos que los originarios podrían poseer en un nuevo ciclo sociopolítico que la sociedad chilena comenzaba a vivir en la entrada al siglo veintiuno. Proceso que exhibe la capacidad histórica que una parte de la población indígena ha tenido para construir una conciencia étnica en sí y para sí, concediendo una visión particular de la realidad social en la que están insertos. La evidencia de la información que entregan los relatos que siguen permite atisbar el fenómeno de configurar una conciencia étnica, en un sector de la sociedad prehispánica nacional, que ha autorizado fabricar una percepción positiva de su ser indígena. 


\begin{abstract}
En Belén ocurría algo rarísimo, porque yo bajé del altiplano y todos los chicos de Belén comienzan a tratarme de indio y de boliviano; de hecho, yo venía con hojota, a pesar que conocía el zapato, no estaba tan alejado del mundo. Ahí, estaban los carabineros, antes los conocía también. Entonces, en Belén un día me mandaron a llamar, me están llamando del retén, ya voy: “¿qué será?”, y me dicen: "mire, usted ha llegado hace dos meses acá y no ha venido a hacer aseo, no ha venido ningún domingo aquí al reten y a las caballerizas". Chuta y ¿por qué tengo que venir al aseo?, y quedé sorprendido, mas que estaba niño, entonces, no es que yo no sepa que había que ir. Había un carabinero que me dice: “¿tú eres chileno o boliviano?". Quedó como en duda, por que yo le hablé con mucha fuerza, como chileno le hablé yo; no le hablé con temor, digamos, además que ya había conocido los carabineros allá y no me inspiraban tanto temor como inspiraban a los chicos que no conocían a los carabineros: "¿eh, de dónde eres tú?". "De Ticnámar", le digo. "¿Chileno o boliviano? "Chileno", le digo. Me dice "ique vas a ser chileno, indio!", eso fue un puñal. Además, me lo dice con desprecio, ese puñal me hizo reaccionar después, eso fue un quiebre fundamental para entrar al movimiento indio (Sr. Cornelio Chipana. Dirigente del Pacha Aru. Organización aymara de la Provincia de Arica. Actualmente, SubDirector de la Corporación Nacional de Desarrollo Indígena, Jurisdicción - Subdirección Norte (CONADI). Entrevista, 1 de Abril del año 2000. Líneas: 240 - 254. Pág.: 8 - 9).
\end{abstract}

En esa época, se empieza a reflexionar el tema desde el punto de vista más profundo, de los por qué, cómo, por qué este estrato de indio, por qué el paisano, por qué el paitoco, por qué boliviano (Sr. Zenón Alarcón. Dirigente del Pacha Aru. Organización aymara de la Provincia de Arica. Actualmente, es Consejero Nacional Aymara frente a la CONADI (2004 - 2008). Entrevista, 2 de julio de 1999. Líneas: 156 - 160. Pág.: 7).

Los datos referidos a realidades relacionadas con una valoración de lo indígena en el mundo precolombino otorgaron afirmar en el escrito la siguiente proposición. Los procesos republicanos, primero peruano y luego chileno; las propuestas de modernidad regional; los procesos del capitalismo, todos ellos expresados en el ámbito local de la realidad andina no sólo han sido contenidos de desestructuración del mundo indígena. Al mismo tiempo, esos procesos han establecido, en el recorrer de la historia, particulares dinámicas de continuidad y dinámicas de cambio en el componente andino y en el sentido mentado de la comunidad indígena que permiten, en la actualidad, la vigencia con cambios de la sociedad autóctona de los Andes (Erdmute, 1999, Gundermann, 2001b). Esas dinámicas externas, en conjunto con otras dinámicas propias del mundo andino, han autorizado a los originarios el desarrollo de prácticas de preservación y de innovación, las que han reinventado y reubicado su legado socio-simbólico, en las distintas actualidades donde se han visto envueltos. Asimismo, la vigencia con transformaciones de lo indígena en las sociedades latinoamericanas permite sentenciar al texto. La identidad indígena no se basa en la existencia a priori de un sujeto social nativo, de características étnicas preestablecidas o de entramados culturales esenciales; sino en la articulación social de la diferencia. Plantea, no estudiar las tradiciones inmutables en el pasar de los años, sino reinscribirlas en términos de las contradicciones y de la contingencia de las vidas de quienes forman parte de esas diferencias (Bhabha, 1994). Esta perspectiva teórica, de la continuidad histórica discontinua de los pueblos indígenas en la comunidad nacional chilena, apartó al manuscrito de programas de investigación edificados en los principios científicos de la desintegración o de la desmantelación de la realidad indígena frente a los procesos ocurridos desde el colonialismo español en tierras americanas. Sin embargo, una postura de la rearticulación de las diferencias étnicas no obvió en su reflexión los procesos de violencia simbólica, psicológica, física y estructural que la sociedad indígena del Norte de Chile, y los demás pueblos precolombinos, han sufrido en su relación con el Estado moderno (González, 2001, 2003, 2004d). Tampoco ha implicado para el texto negar la condición de oprimido y su ubicación de dominado que, históricamente, las poblaciones indígenas han experimentado, con diferentes matices, en el seno de las formaciones sociales latinoamericanas. 
Empero, los efectos del Acuerdo de Nueva Imperial no han permanecido sujetos solamente a la dimensión identitaria para la sociedad civil indígena, donde ha existido una valorización positiva de su legado prehispánico, sino que además, el protocolo político de 1989 ha permitido a los originarios abrir la discusión sobre el prototipo de sociedad nacional que se debe construir en Chile para enfrentar el siglo veintiuno. Desde la retina nativa, el Estado en la actualidad debería asentar las bases de una sociedad multicultural dotada de relaciones interculturales para la vinculación del mundo indígena con la sociedad civil no indígena.

Este es el arquetipo de sociedad que pasa por la construcción de un nuevo ordenamiento jurídico, que contenga una serie de soportes legales y con un conjunto de protecciones institucionales, para apoyar la adecuada protección y la promoción de las culturas precolombinas en la comunidad nacional. Sólo así se comenzaría, lentamente, la edificación de una sociedad multicultural o pluriétnica que, para los indígenas, debe expresarse en una educación intercultural bilingüe; en la socialización de su historia y de su cosmovisión precolombina; en preservar su lengua nativa; en gobiernos locales indígenas; en una salud que complemente conocimientos modernos con los conocimientos medicinales prehispánicos; con el rescate de la ciencia y de la tecnología indígena; con aplicar la ley de la costumbre; con derechos colectivos para las agrupaciones vernáculas de la América morena; entre otras formas en que se debe fomentar una sociedad multicultural en territorio chileno.

En el siguiente segmento discursivo, extraído desde la reflexión de los oriundos de los Andes, se manifiesta la necesidad de promover hoy la construcción de una sociedad sobre la base del respeto de la diversidad cultural, antes de seguir con el fomento de una política de asimilación nacional en la realidad social indígena.

\begin{abstract}
No somos iguales que los demás, no somos iguales, en las concepciones que tenemos, incluso de tiempo. Lamentablemente, yo no hablo en aymara. Pero, otras personas tienen el lenguaje diferente a los demás, no todos los chilenos hablan en aymara, si todos los demás chilenos habláramos en aymara, tengamos todos lo mismo, pero no todos los chilenos hablan aymara, los otros chilenos no basan su alimentación en lo que da la Pacha, todo lo que les brinda la Pachamama, lo toma el aymara, desde ese punto de vista no somos iguales. Por lo tanto, el Estado tiene que tener unas prácticas diferentes, porque somos un grupo diferente (Sra. Fresia Vilca. Dirigente de Aymar Marka. Organización aymara de la Provincia de Iquique. Actualmente, es funcionaria del departamento de Educación y de Cultura de la Corporación Nacional de Desarrollo Indígena, Jurisdicción - Subdirección Norte (CONADI), Entrevista, 26 de junio de 1999. Líneas: 746 - 753. Pág.: 24).
\end{abstract}

Una maqueta de sociedad pluriétnica, propuesta por el mundo indígena, lleva en su seno una crítica al modelo clásico de Estado-nación moderno, que se sustenta en los contenidos de una exclusiva identidad nacional y en el concepto de un sólo pueblo de origen para la población de una particular comunidad de ciudadanos. Así, se permite sostener la ecuación política de una única nación para un Estado. Modelo clásico de Estado moderno, mono nacional homogéneo, que ha personificado tanto en tiempos pasados como en el presente los intereses y los proyectos históricos de las clases dominantes y de las elites de poder (Kymlicka, 2002). Esta formación estatal ha incidido, directa e indirectamente, en la exclusión histórica de las propuestas de sociedad que los pueblos prehispánicos han bosquejado para edificar la comunidad política de iguales en territorio chileno. Los registros orales que siguen esculpen la percepción andina de un trato desigual entre indígenas y no indígenas, 
prácticas que en el tiempo han sembrado una inclusión por exclusión del mundo proveniente de los Andes, como de los demás pueblos indígenas, en la sociedad nacional.

\begin{abstract}
El caso de los Solari, ellos empezaron igual que nosotros, cargando un morral y vendiendo en un carretoncito, incluso, esas familias comenzaron más abajo que nuestro pueblo. Pues, nosotros tenemos ganado, tierras, tenemos de todo. Pero, como ellos generan todo un status por ser colonia de residentes yugoslavos, italianos, poseen una estructura que se mueve de acuerdo al sistema nacional y si uno quiere entrar allí no se puede, no pasa nada (Sr. Zenón Alarcón. Dirigente del Pacha Aru. Organización aymara de la Provincia de Arica. Actualmente, es Consejero Nacional Aymara frente a la CONADI (2004 - 2008). Entrevista, 7 de julio de 1999. Líneas: 234 - 241. Pág.: 8).
\end{abstract}

Por decir, todas las políticas están dirigidas al ciudadano común del país, para todos era igual, entonces en ese trato igualitario nosotros perdíamos, o sea si aquí es igual para todos y aquí éramos tres, naturalmente que nosotros vamos a ser los últimos. Ese trato general repercutía fuertemente en nosotros. Esto es en todo orden de cosas, por ser si veían a un indígena en el hospital, ni si quiera sabían que era un indígena no existía la palabra aymara, decían: hay un indio, hay un paisano, en fin que estaba ahí, tampoco él hablaba, y quedaba para el final, quedaba para el final (Sr. Javier Vilca. Dirigente de la Corporación Provincial aymara, COPRAY. Organización aymara de la Provincia de Iquique. Entrevista, 27 de julio de 1999. Líneas: 181 - 184. Pág.: 6).

La propuesta de un Estado moderno tejido en la heterogeneidad de culturas busca finiquitar la visión homogénea de nación, donde la única identidad política que pueden manifestar los indígenas para interactuar en la sociedad nacional es la chilena; pues en un modelo de Estado pluriétnico la población prehispánica, aparte de mantener su identidad política nacional para una vinculación con la sociedad no indígena y con los servicios estatales, también gozaría de una identidad política étnica (kymlicka, 2002). Para el caso de la sociedad nativa de los Andes esa identidad política étnica se relaciona con su raíz inkacika y con su origen Tiwanaku. El siguiente relato extraído desde un diario local chileno exhibe la permanencia en el mundo andino de una memoria histórica indígena que, en la actualidad, es objeto de relecturas por parte de los vernáculos de los Andes regionales ya sea para exponer sus demandas ciudadanas, ya sea para manifestar su visión de un cierre de su historia indígena producto de la conquista hispana o ya sea para recordar un pasado distinto al occidental.

\begin{abstract}
La nación del Tawantisuyu, se inició en la isla del Titicaca con los inkas Manko Capak y Mano Oklluk, considerados los hijos del Sol y la Pachamama, quienes con su sabiduría fundaron la comunidad del Cuzco, el ombligo de la gran nación del Tawantisuyu, que significa cuatro regiones integradas unas a otras. Los kollasuyus que se ubicaron al sur del Cuzco. Luego la región del Kuntisuyu, al oeste. La región del Antisuyu, en la región de la selva y los pueblos que estaban al centro del Cuzco, y que se denominó Chinchasuyu. Estas cuatro regiones conformaron lo que más tarde pasó a conocerse como la gran nación y civilización del Tawantisuyu. Cabe destacar que el Tawantisuyu se fundó en el 1.200 D.C, y duró hasta 1532, fecha en que ocurrió la conquista de América y la llegada de los españoles. Uno de los grandes logros de la nación inkacika fue crear la sociedad colectiva y comunitaria, que respetó la diferencia de los suyus, de acuerdo a la situación geográfica y cultural de los pueblos. El suyu era dirigido por el kuraka, que los colonos simplemente llamaron cacique. En los tiempos del Inka, el trabajo era sinónimo de alegría y felicidad. Esto trajo consigo que nunca existiera el hambre ni la vagancia (Gumercindo Mamani. Dirigente de Aymar Marka. Organización aymara de la Provincia de Iquique, fundador del Centro Cultural Kespikala del pueblo de Mamiña. Diario La Estrella de Iquique, Domingo 21 de enero de 1990. A - 5).
\end{abstract}

Al construir una comunidad nacional basándose en una ciudadanía diferenciada para los pueblos originarios ellos reflexionan que se está recién ahí comenzando un proceso de consolidar, gradualmente, una democracia con mayor participación y con mejor representación de los indígenas en la sociedad chilena. A continuación, se expone la valorización positiva que los originarios depositan en el Estado, en términos de ser una institución necesaria para fomentar la construcción de una sociedad pluricultural y de relaciones interculturales.

Es bueno, porque los tres poderes del Estado incorporan en su agenda la temática indígena, con todas sus aristas que tiene. Ahora, la idea es que el Estado pueda transmitir a la sociedad civil, que debe reconocer el espacio de los indígenas, y que pudiéramos en un mediano plazo no sólo tener un mejoramiento en la calidad de vida de nuestras familias, sino que también mayor participación social y política (Sr. Antonio Mamani. Dirigente de Aymar Marka. Organización aymara de la Provincia de Iquique, ex-Subdirector de la Corporación Nacional de Desarrollo Indígena, 
Jurisdicción - Subdirección Norte (CONADI) 1993 - 1999. Actualmente, Secretario Ejecutivo de la Corporación de los Municipios Rurales de la Provincia de Iquique, 2006. Entrevista, 9 de agosto de 1999. Líneas: 97 - 102. Pág.: 4).

Si bien la población andina ha apostado por el desarrollo de un nuevo pacto de dominación, sobre el respeto de lo indígena, igualmente perciben que tal modelo de Estado-nación multicultural no es un proyecto que será aceptado de inmediato por la clase dominante. Pues, aquel modelo atenta con el enfoque clásico del Estado-nación, donde las elites de poder han apoyado sus proyectos históricos e intereses, simbólicos y materiales, al interior de la sociedad chilena. Para ratificar esta apreciación de la realidad nacional la memoria histórica andina se sostiene en los hechos de obviar, en la presente época, por la clase gobernante y legislativa el reconocimiento constitucional para los pueblos autóctonos y la ratificación del Convenio 169 de la OIT. Estos contenidos, al no estar vigentes, impiden una ordenación jurídica adecuada para fomentar un constitucionalismo pluriétnico, un pluralismo jurídico y una institucionalización de la diversidad cultural (Mansilla, 2004), que son pilares necesarios para construir una sociedad de los contenidos que propone la elite dirigencial indígena en la comunidad política chilena.

\begin{abstract}
El Estado chileno no está preparado para generar tal cantidad de derecho para los pueblos indígenas. No tiene siquiera la oportunidad de generar una alternativa, un escenario como ese, porque las condiciones no están dadas en el sentido que el país tiene una estructura política social-económica basada en el principio de la unidad nacional, y es evidente que el país en Latinoamérica más nacionalista que hay es Chile, más duro en ese sentido, y eso sería romper con su estructura tradicional (Sr. Zenón Alarcón. Dirigente del Pacha Aru. Organización aymara de la Provincia de Arica. Actualmente, es Consejero Nacional Aymara frente a la CONADI (2004 - 2008). Entrevista, 2 de junio de 1999. Líneas: 570 - 582. Pág.: 18 - 19).
\end{abstract}

La sociedad indígena, en un escenario post protocolo político de Nueva Imperial, conserva la tesis de que el Estado es un instrumento para la defensa de los intereses económicos y políticos de los grupos de poder y de las clases dominantes, antes que un instrumento para el fomento y protección de los proyectos históricos de los pueblos indígenas. Con ello, la sociedad precolombina evalúa que su posición de dominado y de subordinado en un escenario de promoción y de valoración de lo étnico y de las culturas locales no ha cambiado en comparación con escenarios históricos pasados, donde esos rasgos eran negados.

El cero avance en aprobar una carta constitucional pluriétnica, la falta de voluntad política para ratificar convenios internacionales que favorezcan una ciudadanía indígena y derechos individuales y colectivos a los pueblos originarios, una institución de fomento del desarrollo de los pueblos indígenas, de carácter estatal y en menor medida representativa de los intereses de la sociedad prehispánica chilena, como es la Corporación Nacional de Desarrollo Indígena (CONADI), la carencia de soportes legales y de protecciones institucionales que permitan resguardar, apropiadamente, las tierras, las aguas y demás recursos naturales que se emplean para la conservación de las sociedades precolombinas en Chile, son indicadores en los que la opinión indígena apoya su apreciación negativa sobre los alcances del Acuerdo de Nueva Imperial. Las reflexiones a seguir manifiestan el malestar de la dirigencia andina por la falta de voluntad de las elites de poder, y de los partidos políticos, por avanzar en un modelo de Estado y de sociedad de mejor representación y de mayor participación de los pueblos indígenas.

(C) René Patricio Aguilera Barraza. Publicado en AIBR. Revista de Antropología Iberoamericana, Ed. Electrónica 
Si hubiéramos seguido sin Ley Indígena, creo que estaríamos en pie de lograr una cosa probablemente con mayor fuerza, pero al haber obtenido una Ley Indígena y al estar sujeta a la Conadi, una institución del Estado, la Ley Indígena queda sometida a quien dirija la Conadi. La Ley Indígena es están flexible que puede llegar un momento, a operar como una Ley más, sin la pertenencia cultural y la Conadi convertirse en una institución más del Estado (Sra. Fresia Vilca. Dirigente de Aymar Marka. Organización aymara de la Provincia de lquique. Actualmente, es funcionaria del departamento de Educación y de Cultura de la Corporación Nacional de Desarrollo Indígena, Jurisdicción Subdirección Norte (CONADI). Entrevista, 26 de junio de 1999. Líneas: 370 - 376. Pág.: 12).

Este escenario no nos gusta, pues muchas cosas para el desarrollo indígena no dependen de las potencialidades de los indígenas, sino que derivaran de la concertación de partidos políticos, por ejemplo, el cupo de la Subdirección Conadi - Norte, es P.P.D. (Partido por la Democracia, que es parte de la Concertación de Partidos por la Democracia, actual bloque político de Gobierno) (Sr. Zenón Alarcón. Dirigente del Pacha Aru. Organización aymara de la Provincia de Arica. Actualmente, es Consejero Nacional Aymara frente a la CONADI (2004 - 2008). Entrevista, 2 de junio de 1999. Líneas: 617 - 623. Pág.: 20).

Aunque, el Acuerdo de Nueva Imperial ha permitido generar un vuelco de ciento ochenta grados a las relaciones que la sociedad prehispánica entabla con el Estado, en la conciencia colectiva andina la política de promoción de lo indígena que realiza la administración estatal es una acción simbólica. Pues, si bien existe un reforzamiento de los procesos de valorización de su identidad étnica, aquello no se ha acompañado con el desarrollo de marcos jurídicos pertinentes o con el reordenamiento del soporte legal chileno para proteger la base material de los pueblos originarios, sus tierras y sus aguas, principalmente. Esta situación facilita, en la presente época, la expropiación de tierras, la sobreexplotación del factor hídrico y el uso indiscriminado, por parte de los proyectos económicos, de los recursos naturales que existen en territorio nativo. Tal escenario sociopolítico ha llevado a establecer al mundo indígena que la multiculturalidad es una política funcional a las acciones del sistema económico capitalista. Lo indígena se ha convertido en un contenido de adorno en la práctica discursiva del Estado. Pues, si bien las administraciones estatales hoy en día utilizan en su lenguaje político contenidos como comunidad, multiculturalismo, interculturalidad, minorías étnicas, los nativos no observan en el accionar gubernamental un cambio en las relaciones de desigualdad, de explotación y de dominación que las agrupaciones originarias viven cotidianamente en Chile. Sentenciando la conciencia social indígena que la multiculturalidad no es sinónimo de bienestar ni de progreso para los pueblos precolombinos.

Uno de los mecanismos en que los nativos ven un instrumento, adecuado, para fomentar el desarrollo de sus pueblos en territorio nacional es el Convenio 169 de la OIT. Los comentarios a seguir, enseñan los efectos que ve la sociedad oriunda de los Andes en una posible aprobación del Convenio 169 de la OIT para su realidad indígena.

Bueno, uno porque es el tratado de acuerdo a lo poco que yo he leído, que preserva al medio ambiente, preserva a los indígenas, como pueblo prácticamente, entonces si hoy en Chile no están protegidos los indígenas, debería estar ratificado y ser complemento para nosotros y no ser el único instrumento la ley indígena, y ahí nosotros realmente nos sentiríamos protegidos, ya no estaríamos en un problema, como lo esta teniendo la gente en el Parque Lauca, porque habrían tratados internacionales para protegernos (Sra. Fresia Vilca. Dirigente de Aymar Marka. Organización aymara de la Provincia de Iquique. Actualmente, es funcionaria del departamento de Educación y de Cultura de la Corporación Nacional de Desarrollo Indígena, Jurisdicción - Subdirección Norte (CONADI). Entrevista, 23 de octubre de 1999. Líneas: 296 - 299. Pág.: 13).

El convenio 169 de la OIT, sería interesante como instrumento de relación entre Estado y pueblos indígenas, porque la garantía que tiene el convenio 169 de la OIT., es que le da al indígena derecho a reclamar. Nosotros firmamos el acta de Nueva Imperial, pero donde reclamamos, ahora que el gobierno no cumplió. Con el convenio 169 de la OIT., podemos legitimarnos en las cortes internacionales, pues el convenio da la garantía y el status de pueblo a nuestras sociedades (Sr. Zenón Alarcón. Dirigente del Pacha Aru. Organización aymara de la Provincia de Arica. Actualmente, es Consejero Nacional Aymara frente a la CONADI (2004 - 2008). Entrevista, 2 de junio de 1999. Líneas: 670 - 676. Pág.: 21 - 22).

(C) René Patricio Aguilera Barraza. Publicado en AIBR. Revista de Antropología Iberoamericana, Ed. Electrónica Vol 1. Num. 2. Marzo-Julio 2006. Pp. 311-330 Madrid: Antropólogos Iberoamericanos en Red. ISSN: 1578-9705 
Para la conciencia social indígena el reforzar la autonomía de los pueblos prehispánicos no ha significado sólo proponer modificar los cimientos tradicionales de la democracia, de la ciudadanía y del Estado-nación, igualmente el fomentar el desarrollo autogestionado de los pueblos vernáculos en territorio nacional implica generar nuevas modalidades de integración de los originarios a la comunidad política nacional. Desde la evidencia de los datos una propuesta de reestructuración de las bases del Estado moderno y de sus contenidos de soberanía, de ciudadanía, de independencia y de democracia, no busca atentar contra la unidad territorial del Estado-nación moderno. Por lo tanto, pensar que el reconocimiento de la diversidad cultural que buscan hoy los pueblos indígenas llevaría a la autodestrucción de las bases del Estado-nación en la realidad sociopolítica chilena, y en realidad latinoamericana actual, es una reflexión exagerada. Ya que, los procesos sociohistóricos exhiben que la vigencia de la estructura del Estado-nación moderno, como una construcción histórica, no desaparecerá en un futuro previsible. Sin embargo, tal proceso de continuidad del Estado-nación a partir de los relatos de la dirigencia andina, en el presente escenario sociopolítico, no puede ser igual a su génesis del S. XVIII y S. XIX. Entre estas nuevas condiciones que debe poseer el Estado-nación para seguir rigiendo la vida de los ciudadanos es la presencia en su anatomía de las diferentes identidades etno-culturales que existen en su seno, las que en tiempos antiguos se habían negado o se habían despreciado por la política estatal y por la sociedad civil (Kymlicka, 2002).

La conformación de un Estado multicultural permitiría a los grupos indígenas poseer algún grado de autonomía para materializar sus proyectos históricos, para administrar sus territorios, para aplicar la ley de la costumbre, para preservar su lengua e historia, entre otras situaciones. Ya que, un Estado multicultural modelo que, en la actualidad, se consolida en las democracias occidentales para regular las relaciones entre grupos étnicos y Estado, las elites de poder y las clases dominantes estarían en la generación de un marco de respeto de los derechos humanos de los pueblos originarios, siendo percibido por la sociedad prehispánica como un avance cualitativo en las relaciones sociopolíticas entabladas históricamente entre indígenas y no indígenas.

Sin embargo, en un contexto de contradicciones, de conflictos, de avances y de paradojas en torno a la temática indígena, la dirigencia andina apunta a seguir en los procesos de institucionalización de la diversidad cultural. Pero, con el objetivo de ir, lentamente, desde una sociedad multicultural a una formación social intercultural. La relevancia de pasar desde una sociedad pluricultural a una de características interculturales es que no sólo se concede el reconocimiento a la diferencia de los pueblos indígenas, sino que además existe la posibilidad de transformación de las relaciones asimétricas entre pueblos indígenas y Estado, incluyendo sus instituciones sociales, políticas, económicas y jurídicas (Walsh, 2002). La evidencia de la información a presentar ilustra los objetivos futuros que se deben afrontar para mejorar la participación y la representación de los pueblos indígenas en la comunidad nacional chilena.

La demanda indígena pasa por mayor participación, que podamos influir fuertemente en un cambio de la institucionalidad, poseer gobernadores, alcaldes indígenas, sintonizar cada vez la posición de los alcaldes con la posición de nuestro pueblo. Esta etapa se relaciona con la recuperación de mejores derechos para los indígenas. Yo creo, que la futura legislación nacional debería reflejar a los pueblos indígenas. Pues, hoy la ley indígena podría ser 
derogada, pues están hambrientos muchos sectores por hacerla desaparecer. Pero, si estamos dentro de la constitución nacional, obviamente la cosa va ser más complicada, no van a poder hacer modificaciones tan fáciles para sacarnos, pues seremos parte esencial en la sociedad chilena. Con ello, iremos ganando nuestro espacio de autonomía, para accionar nuestra costumbre, nuestras tradiciones, regular nuestra lengua, esos son los desafíos de hoy (Sr. Zenón Alarcón. Dirigente del Pacha Aru. Organización aymara de la Provincia de Arica. Actualmente, es Consejero Nacional Aymara frente a la CONADI (2004 - 2008). Entrevista, 2 de junio de 1999. Líneas: 710 - 717. Pág.: 22)

En la actualidad, no tenemos una interlocución formal con el Estado, bueno esta el Consejo de la Conadi, pero depende de un Ministerio y si el Presidente quiere truncar una decisión toma medidas, la injerencia indígena es menor. Hoy debemos construir una contraparte formal sin nexo con el Estado para dialogar con él, como es en otros países (Sr. Carlos Inquiltupa. Dirigente del Pacha Aru. Organización aymara de la Provincia de Arica, ex Consejero Nacional Aymara frente a la CONADI. Actualmente, es Encargado de la Unidad de Desarrollo Indígena de la Corporación Nacional de Desarrollo Indígena, Jurisdicción - Subdirección Norte (CONADI). Entrevista, 15 de marzo de 2000. Líneas: 110 - 113. Pág.: 4).

El desafío de la demanda indígena, entonces, no sólo ha apuntado a lograr el reconocimiento de los pueblos originarios en un escenario sociopolítico posterior al Acuerdo de Nueva Imperial. Más bien, en la subjetividad andina el contenido de la multiculturalidad ha sido un argumento para debatir, desde los pueblos precolombinos con las administraciones del Estado, la necesidad de fundar una institucionalidad plural jurídica para Chile que permitiría normar las relaciones entre población nativa y no indígena a través del reconocimiento del derecho indígena o consuetudinario (Mansilla, 2004). Para la percepción andina, la institucionalización de un pluralismo jurídico contribuiría a un mejor empoderamiento de los pueblos originarios en la comunidad política nacional. Pues, el reconocimiento de los pueblos precolombinos por parte del Estado-nación, necesariamente debe llevar a la existencia y a la coexistencia de sistemas normativos (supuestamente en términos de igualdad) para una sociedad nacional (Walsh, 2002). Por lo anterior, la promulgación de la Ley Indígena $\mathrm{N}^{0} 19.253$, donde se establecen las normas de protección, de fomento y de desarrollo de los indígenas no ha bastado desde el punto de vista indígena para la transformación de las relaciones asimétricas que sostienen los pueblos originarios con la comunidad política nacional. De ahí, la necesidad de promocionar en el discurso prehispánico chileno una institucionalización de un pluralismo jurídico que otorgaría la transformación del Estado, de sus instituciones, de su ordenamiento legal y de la sociedad civil nacional para una mejor inclusión de los pueblos originarios a la estructura social chilena. Requisitos fundamentales para el desarrollo de un ordenamiento plural jurídico, donde coexista el derecho positivo con el derecho ancestral, son el reconocimiento constitucional y la ratificación de convenios internacionales de protección al indígena. El cimiento que otorgarían esos marcos legales, desde la conciencia andina, facilitaría, en un futuro no muy lejano, comenzar a construir una sociedad intercultural, en donde exista una democracia representativa de los distintos grupos sociales, prehispánicos y no indígenas, mediante una ciudadanía que fomente, adecuadamente, la participación de los originarios en los proyectos de sociedad que se construyen para la comunidad nacional chilena.

Para la psiquis social nativa de los Andes el Acuerdo de Nueva Imperial no ha representado el fin de las desigualdades para los pueblos indígenas. Por lo tanto, el análisis que se realiza de él en términos generales no ha sido positivo. A pesar, que tal hito histórico ha permitido al discurso indígena articular componentes como: identidad, comunidad, derechos colectivos, entre otros contenidos, permitiendo abrir la discusión en torno a temáticas tales como: generar un nuevo modelo de Estado-nación; 
promover la construcción de una sociedad intercultural; la búsqueda del reconocimiento de un pluralismo jurídico para regir las relaciones entre indígenas y Estado; entre otros tópicos. Contenidos que autorizan afirmar la búsqueda de los pueblos vernáculos, en el siglo veintiuno, de un nuevo pacto de dominación con las elites de poder que administran al Estado. Tal protocolo político no ha cumplido las expectativas de la sociedad indígena.

Para ello, el mundo nativo estima que los procesos y las transformaciones que ha experimentado la sociedad chilena, especialmente, desde los años ochenta en adelante impiden avanzar en la materialización de sus demandas al ritmo de otras realidades indígenas de Latinoamérica como son: Ecuador, México, por nombrar algunas. Pues, en la comunidad nacional los enclaves autoritarios, la constitución de 1980, la ideología de la doctrina de seguridad nacional, un sistema de elección binominal, donde pueden participar sólo los bloques de partidos políticos tradicionales, el rol tutelador de las Fuerzas Armadas sobre la sociedad, la ideología del nacionalismo, han sido un atascadero de toda aquella acción que ha buscado desprender las relaciones sociales y económicas de un pasado autoritario y nacionalista en Chile. En la subjetividad andina el trauma dictatorial de los años ochenta incide, directa o indirectamente, en las elites de poder y en las clases dominantes para generar un contexto sociopolítico a favor de los pueblos originarios en nuestros días.

\footnotetext{
El nacionalismo, el patriotismo existe desde antes, pero con Pinochet se acentuó, se concentró más, pero eso ya existía (Sr. Javier Vilca. Dirigente de la Corporación Provincial aymara, COPRAY. Entrevista, 4 de junio de 1999. Líneas: 183 - 186. Pág.: 6).

Otro elemento relevante es el de la doctrina seguridad nacional, se insiste en resguardar la soberanía, la patria, si no estas de acuerdo con esos principios, eres catalogado de no cumplir con los deberes de la patria y todo eso (Sr. Zenón Alarcón. Dirigente del Pacha Aru. Organización aymara de la Provincia de Arica. Actualmente, es Consejero Nacional Aymara frente a la CONADI (2004 - 2008). Entrevista, 7 de julio de 1999. Líneas: 470 - 476. Pág.: 15).
}

Pero el legado de la dictadura militar no es el único obstáculo para lograr una sociedad de las características que reflexiona la elite dirigencial indígena. Además, la discriminación hacia la población precolombina es otro componente que impide avanzar en la demanda actual de los pueblos originarios. Los registros orales que se presentan dibujan un cuadro de las relaciones coloniales y de discriminación que la sociedad andina ha sufrido en contextos pasados antes del Acuerdo de Nueva Imperial y que en la actualidad se mantienen sobre los originarios en Chile. En el primer relato, se expone la visión de un comunero andino sobre la temática del indio; en la segunda narración las paradojas de la educación para el indígena; y en el tercer discurso, la práctica de la discriminación como un patrimonio sociocultural de contextos pasados que hoy sigue vigente e impide una adecuada integración de los indígenas en la formación social.

Siempre nos trataban mal, unos y otros nos trataban de indios. Que el indio no sabe nada, es un ignorante. En la ciudad nos trataban de indios y cosas así (Sr. Felipe Caqueo, agricultor de la comuna de Camiña, Provincia de Iquique, Chile. Entrevista 11 de enero de 1998. Líneas: 35 - 37. Pág.: 2. Información cedida por el Dr. Hans Gundermann Kröll).

Yo creo que no, para nada, imagínate y te pongo un sólo caso, el mejor alumno era Aliro Cayo en mi curso, estoy hablando cuando iba en primero básico o segundo el año 70', entonces, al Aliro el profesor lo agarraba a palo igual en el colegio Lincoyan en Arica y lo agarraban a palo, al hombre le pegaban por cualquier cosa y él era excelente alumno con mejor nota, el profesor le tenía una fobia, bueno a todos los que tenían un carácter indígena. Decía: "los indios, estos indios, el boliviano", cuando se enojaba, porque el profesor estaba bien, el profesor enseñaba y todo disciplinado, pero el hombre si se enojaba, los otros muchachos se podían portar mal, pero eran más castigados los compadres de color café. Estamos hablando, supuestamente, que la educación nos daba un status, que daba una 
posición determinada, que si éramos buenos en el terreno de ellos íbamos a tener algo de respeto, pero no fue así (Sr. Zenón Alarcón. Dirigente del Pacha Aru. Organización aymara de la Provincia de Arica. Actualmente, es Consejero Nacional Aymara frente a la CONADI (2004 - 2008). Entrevista, 2 de junio de 1999, Arica. Líneas: 345 351. Pág.: 11)

Que la discriminación, sigue siendo un elemento fuerte, sigue siéndolo. Si bien, algunos aymaras lo han superado, en otros sigue siendo una barrera, pues hay sectores de la sociedad en donde la discriminación es más fuerte, es más agresiva, que imposibilita nuestra integración (Sr. Javier Vilca. Dirigente de la Corporación Provincial aymara, COPRAY. Entrevista, 7 de julio de 1999. Líneas: 278 - 282. Pág.: 9).

Un contexto de valorización de lo indígena no ha suspendido los procesos de exclusión que siguen experimentando los andinos y demás pueblos originarios, en Chile. Pues, desde la sociedad civil y desde las instituciones estatales en el interactuar con la población indígena de los Andes se continúan reactualizando una serie de categorías como son: la clasificación colonial de indio; definiciones de extranjero como la figura de peruano y de boliviano; además de otras rotulaciones que establecen una percepción negativa de su identidad indígena como: paitocos, llamo, entre otras etiquetas sociales que han gatillado históricamente un proceso de discriminación y de negación de la sociedad nacional sobre los indígenas en su incluir a la formación social regional y nacional. Por lo que, en la memoria histórica andina un nuevo pacto de dominación con el Estado sobre la base de contenidos de lo indígena y del respeto de las culturas precolombinas no ha simbolizado, únicamente, un proyecto de integración para la población prehispánica a la comunidad nacional chilena; sino que también, ha personificado relaciones de exclusión por sus rasgos indígenas que han dado como resultado un incluir por exclusión de los pueblos originarios en la formación social nacional.

Los hechos históricos, los discursos y las opiniones en torno a los impactos del Acuerdo de Nueva Imperial han presentado que el pacto de dominación, sobre la base de lo multicultural, para la subjetividad de la dirigencia nativa de los Andes es un protocolo político agotado e incompleto, no sólo por los contenidos que todavía no poseen una aprobación por parte de las elites de poder que influyen el actuar del Estado como son, el reconocimiento constitucional y la ratificación del convenio 169 de la OIT; sino que además, por las condiciones estructurales de la comunidad política nacional, la que está en un desfase con el discurso de la multiculturalidad. Pues, el legado histórico de Chile, que se sustenta fuertemente en una ideología nacionalista, profundizada con la dictadura militar de Augusto Pinochet incide, directa e indirectamente, en las relaciones de los indígenas con el Estado y con la sociedad civil no indígena, dando como resultado prácticas de negación y de exclusión de los originarios en la formación social nacional actual. Por lo tanto, si bien el discurso oficial y público comenta, entre otras temáticas, la valorización y el respeto por lo indígena, aquello en lo cotidiano no es una práctica común. De ahí, que la sociedad indígena sostiene, en un escenario de discusión de un Estado multicultural, que su posición de dominado y de subordinado, en su cotejar con el pasado no ha cambiado, sus intereses y sus proyectos históricos siguen sometidos a los intereses y a los proyectos nacionales, que dan un incluir por exclusión del mundo prehispánico en Chile. 


\section{Comentarios finales}

La evidencia de la información presentada en el escrito permitió elaborar las siguientes conclusiones referidas a la evaluación del Acuerdo de Nueva Imperial y sus impactos en la realidad social indígena, específicamente en la dirigencia aymara.

Una primera conclusión sentencia que se ha conservado en el pensamiento andino una percepción del Estado independien

te del contexto histórico. El Estado es entendido como la autoridad última para ordenar la realidad social y para resolver los conflictos, principalmente, relacionados con sus territorios indígenas y con los recursos naturales depositados en ellos. Tal percepción sobre el Estado, como agente de máxima autoridad para los prehispánicos, no sólo expuso la capacidad de dominación y de desintegración que ha tenido esa entidad en su realidad social; sino que además, exhibió que el Estado, desde la mirada indígena, representa en estos días un instrumento político que permitiría construir un modelo de sociedad con mayores posibilidades de participación y de mejor representatividad de los pueblos precolombinos en la comunidad política nacional.

Una segunda conclusión, la evidencia de los datos señala que el Acuerdo de Nueva Imperial ha permitido, en el presente escenario sociohistórico, a los indígenas modificar su lenguaje político otorgando remozar el discurso ciudadano que históricamente ha dirigido a las administraciones del Estado. Discurso nativo que comunica hoy la propuesta de un nuevo modelo de Estado y de sociedad para Chile que habilite regir las relaciones entre elites de poder y sociedad civil prehispánica y no indígena, desde relaciones interculturales. Tal Propuesta lleva en su vientre una crítica al prototipo clásico de Estado-nación moderno, caracterizado por ser mono-nacional homogéneo, que se ha materializado en los contenidos de una identidad nacional y en el concepto de un solo pueblo de origen. Modelo clásico de Estado moderno que para los indígenas tanto en tiempos pasados como en el presente ha personificado los intereses y los proyectos históricos de las clases dominantes que han dado, en el recorrer de la historia chilena, una integración por exclusión de los indígenas en la comunidad política nacional y de discriminación de la sociedad civil indígena a los vernáculos de la América morena situados en territorio chileno.

En la actualidad, el desafío que la dirigencia indígena plantea para edificar, lentamente, un Estado sobre la base de la heterogeneidad cultural, que implicaría redefinir los conceptos de ciudadanía y de democracia, con el propósito de conceder reales mecanismos para la inclusión de los indígenas en la formación social nacional pasa por promover el desarrollo de un pluralismo jurídico, el reconocimiento constitucional y la ratificación del convenio 169 de la OIT. Instrumentos legales que fomentarían un constitucionalismo pluriétnico y una institucionalización de la diversidad cultural. Sólo así, la dirigencia indígena reflexiona que habría no sólo una protección de la base supraestructural de su sociedad; sino que también, de sus territorios y de sus recursos naturales, que son necesarios para la conservación, en el tiempo, de las sociedades indígenas en la comunidad nacional chilena.

(C) René Patricio Aguilera Barraza. Publicado en AIBR. Revista de Antropología Iberoamericana, Ed. Electrónica 
Una tercera conclusión a partir de la información obtenida en los registros orales establece que: a pesar que la sociedad indígena nacional y su elite política perciben ciertos avances desde los acuerdos del protocolo político de Nueva Imperial que han permitido la creación de una Ley № 19. 253, de fomento y de protección a los originarios en Chile, en términos generales su evaluación es negativa, puesto que lo étnico, lo cultural, lo indígena se han mercantilizado y funcionalizado al modelo de libre mercado imperante en Chile. Una de las causas que puede explicar esta visión negativa de los indígenas sobre un pacto de dominación sostenido en lo multicultural, en nuestros días, se encuentra en la fisura política que experimentó la acción estatal en torno al tema indígena, entre 1973 y 1993. Suspendiendo, en ese tramo histórico, el actuar del Estado en la realidad social precolombina desde un reconocimiento de lo étnico. Generando que la naciente legislación y las acciones de fomento y de desarrollo indígena en territorio nacional posean, en el siglo veintiuno, retrocesos importantes con respecto a la tradición y al actuar histórico del Estado, que en tiempos pasados había desarrollado en la realidad social prehispánica nacional. Sobre todo, en el período sociohistórico de 1938 a 1972, pues desde los gobiernos del Frente Popular (1938) hasta la promulgación de la Ley № 17.729 (1972) se trató de cubrir, con conflictos y con avances, la demanda de la sociedad precolombina nacional. Demanda histórica principalmente de tinte mapuche y desde 1972 con la promulgación de Ley № 17.729 se buscó dar respuesta a las exigencias de las distintas poblaciones indígenas del país. Ya que, en esa Ley se estableció, por primera vez, un cuerpo legal que se refería y definía a los originarios independientemente de sus tierras en todo el país. En su artículo $1^{\circ}$ estableció: "Son indígenas aquellas personas que habitan en cualquier lugar del territorio, formen parte de un grupo que se exprese habitualmente en idioma aborigen y se distingan de la generalidad de los habitantes de la República, por conservar sistemas de vida, normas de convivencia, costumbres, formas de trabajo, provenientes de grupos autóctonos del país". En la conciencia nativa nacional los impactos de la Ley № 17.729 no se percibieron, pues a los seis meses de su promulgación se derogó por la dictadura militar.

Entonces, en 1972 están las bases de un impulso histórico de las administraciones del Estado, por dar una fisonomía multicultural y pluriétnica a la sociedad chilena. Lo que hoy, con bastantes limitaciones se busca implementar con el marco jurídico de la Ley № 19.253. Limitaciones actuales que se deben a los procesos sociojurídicos desarrollados desde 1973 en adelante en Chile. Pues, el ordenamiento sociojurídico implementado en esos años, y que los actuales gobiernos mantienen, se ha dirigido a sostener la acción de inversiones extranjeras y nacionales bajo un modelo de libre mercado. Por lo que, el escenario de acción en que funciona la actual Ley № 19.253 es totalmente distinto al escenario sociopolítico en que se desarrolló el accionar de la política estatal indígena y en el que iba a funcionar la Ley 17.729. Ya que, los ordenamientos sociojurídicos pasados iban en una tendencia histórica, gradual, relacionada con el reconocer y devolver derechos ancestrales a los pueblos originarios sobre sus territorios y sobre sus recursos naturales. Aquella tendencia histórica en la actualidad no se continúa, sino que mediante la acción estatal en torno a la temática indígena se da todo lo contrario. Pues, si bien hoy se reconoce la existencia de las poblaciones indígenas en Chile, el ordenamiento sociojurídico nacional no esta acorde al espíritu de la Ley $N^{0} 19.253$, es decir, no se 
protegen los derechos ancestrales de los pueblos originarios. En nuestros días, los Códigos de Minería, de Aguas, Civil, la Constitución, Ley de Monumentos Nacionales, entre otros marcos legales, en donde algunos de ellos han sufrido modificaciones substanciales, permiten el uso indiscriminado de los recursos tierras y aguas a favor de los proyectos económicos, sin una adecuada protección de los derechos consuetudinarios de los pueblos originarios. Dos ejemplos de la contradicción del orden jurídico nacional en materia de política indígena son: Un primer ejemplo, los principios en que se levanta la constitución vigente, pues mientras la Ley Indígena promociona una diversidad cultural para la realidad social chilena mediante su artículo $1^{\circ}$, donde señala: "Es deber de la sociedad en general y del Estado en particular, a través de sus instituciones respetar, proteger y promover el desarrollo de los indígenas, sus culturas, familias y comunidades, adoptando las medidas adecuadas para tales fines y proteger las tierras indígenas, velar por su adecuada explotación, por su equilibrio ecológico y propender a su ampliación". La actual constitución política de la República de Chile, en su capítulo I de las bases de la institucionalidad, establece todo lo contrario. En sus artículos 3 y 5 señala una visión homogénea de país, sobre la base de una única identidad nacional, la chilena, dificultando en la realidad social actual la promoción y la materialización de una acción multicultural real. Por lo que, el marco jurídico de la Ley Indígena de 1993 esta sometido y subordinado a la concepción homogénea de la nación chilena guardada en la constitución. Un segundo ejemplo, las modificaciones al Código de Aguas realizadas en 1981. Antes de ese período se establecía la no separación de agua y de tierras, se respetaba la lógica de uso y los derechos ancestrales de los propietarios indígenas sobre sus territorios y sobre sus recursos naturales. Desde 1981 con el nuevo Código de aguas aquella realidad legal cambió, se estableció la noción de separación de la tierra del recurso hídrico para adquirir derechos de inscripción sobre el factor agua. Es decir, no fue necesario poseer tierra para acceder a las fuentes acuíferas en una región de población indígena. Todo ello, con el propósito de proveer del componente hídrico a los proyectos de desarrollo minero. De esta forma, el agua adquirió un status de mercancía que se pudo promover en un mercado, trayendo como consecuencia directa el no respeto de los derechos históricos de la población indígena sobre sus territorios y sobre los recursos naturales al interior de esos territorios. Además, de afectar el funcionamiento de sus economías nativas. De ahí, que se plantea que, en la actualidad, la política indígena estatal posee retrocesos y está recién en un estado embrionario para ofrecer garantías a la sociedad indígena en su relación con el Estado y con la sociedad civil no indígena. Por lo que, su posición de dominado y de subordinado de épocas pasadas no ha cambiado con los contenidos del Acuerdo de Nueva Imperial en Chile, desde los comentarios de la elite dirigencial aymara.

Una última conclusión, la demanda indígena hoy se dirige al fomento de un pluralismo jurídico, que permitiría no sólo el reconocimiento de las culturas precolombinas en Chile; sino que también, concedería transformar las relaciones de poder asimétricas entre Estado y pueblo indígenas, inclusive de sus instituciones y de sus estructuras sociales, políticas, económicas y culturales. De esa manera, no sólo se fomentaría la construcción de un nuevo modelo de Estado, de ciudadanía y de democracia para la comunidad política nacional, sino que de respeto de los derechos ancestrales de los indígenas sobre sus territorios. Para la conciencia nativa la materialización de un pluralismo jurídico pasa 
ineludiblemente por el reconocimiento constitucional de los pueblos originarios y por la ratificación del convenio 169 de la OIT, ya que esos instrumentos políticos llevarían al desarrollo de legislaciones apropiadas en educación, en medicina, en ciencia y tecnología, en políticas agrarias, en protección de sus recursos naturales y de su patrimonio arqueológico, entre otras áreas que deben ser atendidas con normativas pertinentes a los pueblos precolombinos de Chile.

\section{Referencias}

\section{Fuentes Secundarias}

Erdmute, Alber (1999). ¿Migración o Movilidad en Huayopampa?. Nuevos temas y tendencias en la discusión sobre la comunidad campesina en los Andes. Lima, Perú: Instituto de Estudios Peruanos.

Bhabha, Homi (1994). El lugar de la cultura. Buenos Aires, Argentina: Ediciones Manantial.

Bengoa. José (2000). La emergencia indígena en América Latina. Santiago de Chile: Fondo de Cultura Económica.

Brachet, Vivián (1996). El pacto de dominación. México, Colegio de México.

Bryan, Tunner (1997). Citizenship Studies: A General Theory. Citizenship Studies, 1 (1): 5- 18. USA.

Colom, Francisco (1997). Razones de Identidad. España: Editorial anthropos.

Convenio 169 de la OIT (1996). Sobre pueblos indígenas y tribales en países independientes. Guatemala: Instituto Centroamericano de Estudios políticos, INCEP.

Foucault, Michel (1997). La arqueología del saber. Madrid, España: Editorial S. XXI.

González, Sergio (2001). La Escuela Fiscal en el proceso de chilenización de Tarapacá (1910 - 1922): un caso de violencia social y xenofobia en Chile. Tesis doctoral Universidad Academia de Humanismo Cristiano, Santiago de Chile.

González. S. (2003). PAX CASTRENSE EN LA FRONTERA NORTE 1884 - 1929. El 'Factor Tarapacá' en el conflicto entre Perú y Chile por Tacna y Arica. Tesis doctoral Instituto de Estudios Avanzados (IDEA), Universidad Santiago de Chile.

González, Sergio (2004). El Dios cautivo. Las Ligas Patrióticas en la chilenización compulsiva de Tarapacá. 1910 - 1922. Santiago de Chile: Ediciones LoM.

Gundermann, Hans (1995). Comunidad indígena y ciudadanía. La experiencia en el norte de Chile. Revista Allpanacis 2 (46): 91 - 130. Cuzco, Perú: Instituto de Pastoral Andina. 
Gundermann, Hans (2000). Las organizaciones étnicas y el discurso de la identidad en el norte de Chile, 1980 2000. Comunicación presentada en el 50 congreso Internacional de Americanistas. Simposio: Derecho a la cultura y a la autogestión: experiencias y tendencias de los movimientos étnico - culturales en las Américas; el Estado y la etnicidad, Varsovia, Polonia, 10 - 14 de julio.

Gundermann, Hans (2001). Comunidad, sociedad andina y procesos socio-históricos en el norte de Chile. Tesis doctoral, Centro de Estudios Sociológicos, Colegio de México.

Gundermann, Hans (manuscrito no publicado). Cultura andina y globalización, dinámica de la cultura andina en el norte de Chile durante la segunda mitad del S.XX.

Gundermann. Hans (2002). Sociedad aymara y procesos de modernización durante la segunda mitad del Siglo XX. Comunicación presentada Comisión de Verdad Histórica y Nuevo Trato. Grupo de Trabajo Pueblos Indígenas del Norte. SubGrupo de Trabajo Pueblo Aymara, Chile.

Ibáñez, Tomás (1998). Ideología de la vida cotidiana. Barcelona, España: Editorial Sendal.

Jodelett, Denise, Ed. (1998). La representación social, fenómenos, conceptos y teoría. S. Moscovici Psicología Social Tomo II: 469 - 494. España: Editorial Paidos.

Kymlicka. W. (2002): Del Estado nación homogéneo al Estado multinacional. Comunicación presentada en el Seminario sobre la construcción de la Democracia: Ciudadanía y Diversidad. Organizado por el Programa de Naciones Unidas para el Desarrollo Guatemala, 6 febrero.

Ley Indígena 19.253 (1993). Decreto Oficial 5 de octubre, Chile.

Manzilla. A. (2004). El Derecho indígena y las pautas para la conformación de una línea jurisprudencial constitucional en Bolivia. En Cuadernos Electrónicos de Filosofía del Derecho, no 10/2004 (http://www.uv.es/CEFD), ISSN: 1138-9877, Santa Cruz, Bolivia. Accedido el 25 de septiembre del 2005.

Poulantzas, Nicolás (1980). Estado, poder y Socialismo. España: Editorial Siglo XXI.

Poulantzas, Nicolás (1993). Clases Sociales y poder político en el Estado Capitalista. México: Editorial Siglo XXI.

Smith, Anthony (1995). La Identidad Nacional. Madrid, España: Trama Editorial.

Walsh, Catherine (2002). (De) construir la interculturalidad, Consideraciones críticas desde la política, la colonialidad y los movimientos indígenas y negros en Ecuador. Fuller, Norma: Interculturalidad y Política. Desafíos y posibilidades: 15-142. Lima, Perú: Red para el Desarrollo de las Ciencias Sociales en el Perú.

\section{Fuentes Primarias}

Entrevistas realizadas en conjunto con el Profesor Hans Gundermann a los siguientes dirigentes aymaras. En el marco del Proyecto FONDECYT: "De Indio a Ciudadano: Etnicidad, Identidad étnica e incorporación 
indígena a la sociedad Nacional en el Norte de Chile en comparación con los Andes de Perú, Bolivia y Ecuador (1824 -1995)", Nº 19070644.

Alarcón, Zenón (2 de junio, 2 de julio, 7 de julio y 17 de julio del año 1999).Dirigente del Pacha Aru Organización aymara de la Provincia de Arica. Actualmente, es Consejero Nacional Aymara frente a la CONADI (2004 - 2008). Entrevista grabada. Cuaderno No 1. Iquique, Chile. Registro: Dr. Hans Gundermann Kröll y René Patricio Aguilera Barraza.

Caqueo, Felipe (11 de enero del año 1998). Comunero de la Comuna de Camiña. Entrevista grabada. Registro: Dr. Hans Gundermann Kröll. Cedida para la investigación sobre las Representaciones Sociales del Estado que han elaborado las Comunidades Andinas del Norte de Chile. Estudio realizado para obtener el grado de Licenciado en sociología y el Título de Sociólogo.

Chipana, Cornelio (1 de Abril del año 2000) Dirigente del Pacha Aru Organización aymara de la Provincia de Arica. Actualmente, SubDirector de la Corporación Nacional de Desarrollo Indígena, Jurisdicción Subdirección Norte (CONADI). Entrevista grabada. Cuaderno № 2. Iquique, Chile. Registro: Dr. Hans Gundermann Kröll y René Patricio Aguilera Barraza.

Inquiltupa, Carlos (15 de marzo del año 2000). Dirigente del Pacha Aru Organización aymara de la Provincia de Arica, ex Consejero Nacional Aymara frente a la CONADI. Actualmente, Encargado de la Unidad de Desarrollo Indígena de la Corporación Nacional de Desarrollo Indígena, Jurisdicción - Subdirección Norte (CONADI). Entrevista grabada. Cuaderno № 2. Iquique, Chile. Registro: Dr. Hans Gundermann Kröll y René Patricio Aguilera Barraza.

Mamani, Antonio (9 agosto del año 1999) Dirigente de Aymar Marka organización aymara de la Provincia de Iquique, ex-Subdirector de la Corporación Nacional de Desarrollo Indígena, Jurisdicción - Subdirección Norte (CONADI) 1993 - 1999. Actualmente, Secretario Ejecutivo de la Corporación de Municipios Rurales de la Provincia de Iquique. Entrevista grabada. Cuaderno No 1. Iquique, Chile. Registro: Dr. Hans Gundermann Kröll y René Patricio Aguilera Barraza.

Mamani, Gumersindo (1990): Los aymaras creemos que el respeto es clave del progreso. Diario La Estrella, Enero 21, A - 5.

Vilca, Fresia (26 de junio, 23 de octubre del año 1999) Dirigente de Aymar Marka, Organización aymara de la Provincia de Iquique. Actualmente, es funcionaria del departamento de Educación y de Cultura de la Corporación Nacional de Desarrollo Indígena, Jurisdicción - Subdirección Norte (CONADI). Entrevista grabada. Cuaderno No 1 - 2. Iquique, Chile. Registro: Dr. Hans Gundermann Kröll y René Patricio Aguilera Barraza.

Vilca, Javier (4 de junio, 27 de junio, 4 de julio, 28 de noviembre del año 1999) Dirigente de Copray. Organización aymara de la Provincia de Iquique. Entrevista grabada. Cuaderno No $1-2$. Iquique, Chile. Registro: Dr. Hans Gundermann Kröll y René Patricio Aguilera Barraza. 